\title{
A PRÁTICA DA MEDIAÇÃO E DA CONCILIAÇÃO NO TRATAMENTO DA CONFLITUALIDADE SOCIAL PELO PODER JUDICIÁRIO: DISCUSSÃO A PARTIR DA REALIDADE DO ESTADO DO CEARÁ
}

\author{
Igor Benevides Amaro Fernandes ${ }^{1}$ \\ Flávio José Moreira Gonçalves ${ }^{2}$
}

\section{RESUMO}

Estudo acerca dos métodos de tratamento adequado de conflitos com o fito de esclarecer se contribuem de forma efetiva para auxiliar o Poder Judiciário do Estado do Ceará na solução satisfatória dos problemas e demandas judiciais, visando aperfeiçoar a função judicante e garantir uma ampliação do conceito de acesso à justiça para além do mero acesso ao processo judicial.

Palavras-chave: Tratamento Adequado. Conflitos. Solução. Demandas Judiciais. Acesso à Justiça.

\section{THE PRACTICE OF MEDIATION AND CONCILIATION IN THE TREATMENT OF CONFLICT SOCIAL BY THE JUDICIARY: A DISCUSSION FROM THE REALITY OF THE STATE OF CEARA}

\begin{abstract}
Study about the methods of proper treatment of conflicts with the aim of clarifying if the same contribute effectively to assist the State of Ceara Judiciary in the satisfactory solution of the problems and lawsuits, aiming to improve the function judicante and ensure a broadening of the concept of access to justice beyond the mere access to the judicial process.
\end{abstract}

Keywords: Appropriate Treatment. Conflicts. Solution. Legal Demands. Access to Justice.

\section{INTRODUÇÃO}

O Direito é uma ciência dinâmica e os conflitos ocorridos em decorrência da vida em sociedade precisam ser acompanhados em busca da melhor solução para os litigantes. $\mathrm{O}$ acesso à justiça é amplo, sendo direito constitucional assegurado a todo e qualquer cidadão.

\footnotetext{
Mestrando em Processo e Direito ao Desenvolvimento no Programa de Pós-Graduação Stricto Sensu do Centro Universitário Christus (Unichristus). Graduado em Direito pela Universidade de Fortaleza (Unifor).

2 Doutor em Educação (UFC), Mestre em Direito (UFC), Mestre em Filosofia (Uece). Graduado em Direito (UFC). Professor dả graduaçãoo em Direito da Universidade Federal do Ceará (UFC), da Universidade de Fortaleza (Unifor) e do Centro Universitário Christus (Unichristus), instituição na qual atua como professor e pesquisador vinculado ao Programa de Pós-Graduação Stricto Sensu.
} 
Entretanto, o grande problema vivido na atualidade é a demora do Poder Judiciário, em face do grande acúmulo de processos.

Para lidar melhor com os conflitos é necessário compreendê-los como algo intrínseco às próprias sociedades humanas, ou seja, estão presentes em qualquer agrupamento humano estabelecido, sendo até mesmo necessários para a transformação e desenvolvimento social, na perspectiva da própria transformação social e construção da cidadania.

Conforme Carvalho (2008), o Brasil herdou uma tradição cívica pouco encorajadora, tendo em vista que em três séculos de colonização $(1500$ - 1822), os portugueses tinham construído um grandioso país no que tange à unidade territorial, linguística e religiosa, mas deixaram também uma população analfabeta, vivendo numa sociedade escravocrata, de economia monocultora e latifundiária, além de um modelo de Estado absolutista.

Percebe-se, assim, que um fator fortemente negativo para a construção da cidadania foi a escravidão, já que mulheres e escravos estavam sob a jurisdição privada dos senhores, não tendo acesso à justiça para se defenderem. Diante de tal cenário, denota-se que o problema do acesso à justiça no Brasil é algo inerente às nossas raízes coloniais e patriarcais, refletindo-se nas próprias estruturas do Poder Judiciário, as quais repercutiram historicamente todas as formas de desigualdade, a julgar pela forma de recrutar magistrados para o antigo Desembargo do Paço, quando se exigia dos pretendentes ao cargo de magistrado que "“pureza do sangue' do candidato, certificando-se de que nem ele nem seus antepassados eram maculados com sangue 'moro, mulato, judeu ou outra raça infecta"' (Schuartz: 2011, p. 80)

A partir da visão de Cappelletti e Garth (1988), o termo "acesso à justiça” pode ser entendido como o sistema pelo qual as pessoas podem reivindicar seus direitos e/ou resolver seus litígios sob os auspícios do Estado, devendo a acessibilidade ser garantida a todos, bem como produzir resultados que sejam individual e socialmente justos.

De acordo com o que se depreende do art. $5^{\circ}$, LXXVIII, CF/88, o qual foi acrescido a partir da EC n ${ }^{\circ} 45$ de 08 de dezembro de 2004, não se pode conceber que o acesso à justiça corresponda somente ao ingresso em juízo. O grande problema que atinge diretamente o Poder Judiciário atualmente diz respeito ao intuito de se obter uma prestação jurisdicional efetiva, principalmente no que tange ao tempo, impulsionando a maior preocupação atual, que passou a residir em encontrar mecanismos de saída do conflito do Judiciário, a chamada desjudicialização dos conflitos.

Com a Resolução no 125/2010 do Conselho Nacional de Justiça (CNJ) e o advento do Código de Processo Civil de 2015, os anteriormente denominados "meios alternativos de 
resolução de conflitos", em especial, a mediação e a conciliação ganharam mais força e passaram a ser utilizados com maior frequência com o fito de auxiliar o Poder Judiciário no atendimento às demandas e proporcionar maior celeridade e efetividade processual.

Segundo Jorge Neto (2016), o Código de Processo Civil de 2015 inova em muitos pontos, mas não altera a essência do sistema de justiça brasileiro, pelo fato do número de recursos ainda ser enorme e o custo do processo ser considerado baixo para aqueles que dele se aproveitam com o desejo de não cumprir a lei, o que favorece o volume de demandas.

Desta forma, o objetivo geral deste trabalho é analisar a atual situação do Poder Judiciário brasileiro na implementação de políticas voltadas à desburocratização do sistema, especialmente a desjudicialização de conflitos, procurando ainda, como objetivos específicos, compreender o acesso à justiça e sua relação com a efetividade do processo jurisdicional, bem como identificar os principais problemas existentes no Poder Judiciário brasileiro na atualidade e examinar o papel dos métodos de tratamento adequado de conflitos no Código de Processo Civil de 2015 como ferramentas importantes na desburocratização do sistema no Poder Judiciário no Estado do Ceará.

O método de investigação adotado na pesquisa é o sistêmico, utilizando-se de abordagem dialética e crítica a partir de reflexões pautadas nos pilares da pesquisa bibliográfica.

Neste diapasão, busca-se responder a determinados questionamentos, tais como: qual a relação do acesso à justiça com a morosidade do Poder Judiciário Brasileiro? De que modo o Poder Judiciário do Estado do Ceará tem promovido a utilização dos meios de tratamento de conflitos previstos no Código de Processo Civil de 2015? Que mecanismos podem ser implementados para aprimorar o uso da mediação e da conciliação pelo Tribunal de Justiça do Estado do Ceará?

\section{CONTEXTUALIZAÇÃO DO ACESSO À JUSTIÇA}

Merece destacar que o problema do acesso à justiça não é recente, tendo em vista que suas origens remontam ao período do Brasil colonial, considerando a época da independência de Portugal em 1822, onde a escravidão era vista como o fator mais negativo para a construção da cidadania.

Conforme Carvalho (2008), pode-se afirmar que os escravos não eram considerados cidadãos pelo fato de não possuírem acesso a direitos civis básicos, tais como direito à integridade física, à liberdade e à própria vida. Assim sendo, mulheres e escravos estavam sob 
a jurisdição privada dos senhores, não tendo acesso à justiça para se defenderem, já que não existia um poder que pudesse ser chamado verdadeiramente de público. Além disso, ressalta ainda que o período de 1930 a 1945 foi caracterizado como a era dos direitos sociais através da implantação da legislação trabalhista e previdenciária. Todavia, o acesso da população ao sistema judiciário progrediu pouco. Em seguida, o ano de 1964 foi marcado pelo início do período ditatorial, o qual restringiu os direitos civis e políticos pela violência e, consequentemente, contribuiu também para reduzir ainda mais o acesso à justiça.

Carvalho (2008) defende que a Carta Magna de 1988 foi considerada a mais liberal e democrática que o Brasil já teve, sendo assim denominada de Constituição Cidadã pela maior ampliação aos direitos civis, políticos e sociais dos cidadãos. No entanto, o Judiciário ainda não cumpria verdadeiramente o seu papel pelo fato do acesso à justiça ser limitado a pequena parcela da população. Além disso, os custos de serviços de um bom advogado estavam além da capacidade da grande maioria e, apesar de ser dever constitucional do Estado prestar assistência jurídica gratuita aos pobres, os defensores públicos eram em número insuficiente para atender à demanda.

Logo, denota-se que ainda hoje o Poder Judiciário brasileiro atravessa uma longa e grave crise, sendo tal cenário percebido em relação à capacidade de regular e solucionar conflitos. Atualmente, tal Poder vem enfrentando dificuldades de comportar todas as demandas existentes, tendo em vista que a quantidade de lides é muito grande e nem sempre ao resolvêlas, alcança-se o conflito real, a lide sociológica. Por sua vez, é prática corriqueira da sociedade tratar das controvérsias mais simples como uma forma de disputa entre as partes em busca de uma decisão favorável a apenas uma delas sem perceber eventuais interesses comuns, o que revela a presença da cultura de litigiosidade como um traço marcante da vida brasileira.

A criação do Conselho Nacional de Justiça (CNJ), ocorrida com a Emenda Constitucional $n^{\circ} 45$, de 2004, foi uma grande inovação para o Poder Judiciário, tendo em vista que sempre houve resistência por parte de setores da magistratura no que tange à criação de um órgão de controle, planejamento e coordenação do Judiciário. Entretanto, o órgão legitimou-se e, atualmente, não há dúvidas acerca do papel imprescindível deste controle administrativo, inclusive no estabelecimento de metas de gestão bem como, pela primeira vez, na estipulação de uma política nacional de tratamento adequado de conflitos.

Seguindo essa linha de raciocínio, Sauerbronn F. e Sauerbronn J. (2015) afirmam que a criação do CNJ trouxe o foco da administração pública para o Judiciário no sentido de se desenvolver maior atenção à área-meio dentro dos tribunais, passando a estabelecer metas a serem cumpridas pelos tribunais e a punir os membros do Judiciário que não as cumprissem, 
em uma atuação impregnada da essência do gerencialismo que, embora discutível em alguns aspectos, caracterizou a reforma do Estado brasileiro.

Tais autores consideram que, diante do referido cenário, os magistrados passaram a entender necessário dar maior atenção à gestão de suas varas e o CNJ passou a incentivar de forma inequívoca a capacitação de juízes e serventuários, principalmente em disciplinas relacionadas à administração. Mesmo observando grandes resistências, a criação do CNJ contribuiu para dar início a uma maior aproximação dos tribunais em relação à prestação de serviços públicos, considerado este o grande passo para a democratização do acesso à Justiça, no dizer de Oliveira Neto, "acesso à justiça, mais modernamente compreendido como acesso a uma ordem jurídica justa" (2016, p. 7)

Rawls (1981) afirma que existem dois princípios de justiça em relação ao seu acesso: o primeiro, referente à garantia da igualdade na liberdade para todos os indivíduos, ou seja, cada pessoa deve possuir a mais ampla liberdade, devendo esta ser igual à dos outros e a mais extensa possível, na medida em que tenha compatibilidade com uma liberdade similar de outros indivíduos enquanto que o segundo vai tratar da combinação das desigualdades econômicas e sociais de forma a que ambas correspondam à expectativa de que advirão vantagens para todos, bem como que sejam ligadas a posições e a órgãos abertos a todos em condições de igualdade de oportunidades.

Naturalmente, Rawls pontua que, para se atingir o primeiro princípio, todos os cidadãos de uma sociedade justa devem possuir os mesmos direitos básicos, tais como a liberdade política em consonância com a liberdade de expressão; a liberdade de consciência e de pensar, bem como a liberdade pessoal associada ao direito à propriedade e a liberdade de não ser preso arbitrariamente. No que tange ao segundo princípio, Rawls (1981) destaca que, para ser alcançado, faz-se necessária uma maior aproximação entre distribuição de renda e bens, porém, não deve obrigatoriamente ser igualitária, tendo em vista que é importante ser de forma a dar a maior vantagem possível para todos, bem como as posições das autoridades e dos órgãos de comando devem ser também acessíveis a todos, o que explicitamente não acontecia no Brasil Colônia e, certamente, ainda não aconteça materialmente em nossos dias.

Destarte, deve-se buscar o alcance da justiça efetiva pela institucionalização, cultural e estrutural adequada e responsável dos chamados meios "alternativos" de solução de conflitos, não em substituição, mas em complementação à atividade jurisdicional estatal, razão pela qual são considerados "adequados", já que plenamente compatíveis com o Estado Democrático de Direito. São métodos "de tratamento" porque não se propõem a eliminar os conflitos, o que é impossível na vida social e estagnaria o processo de transformação social, 
necessário ao desenvolvimento, mas propõem-se simplesmente a administrá-los, a geri-los, dentro de uma ética do cuidado e da responsabilidade.

Segundo entendimento de Schnitman (1999, p. 18):

Os contextos de resolução alternativos à confrontação, ao paradigma ganhar-perder, à disputa ou ao litígio direcionam-se à co-participação responsável, admitem a consideração e o reconhecimento da singularidade de cada participante no conflito, consideram a possibilidade de ganhar conjuntamente, de construir o comum e assentar as bases de soluções efetivas que legitimem a participação de todos os setores envolvidos.

Numa perspectiva habermasiana, é necessário que os conflitantes se reconheçam como livres e iguais, sentem-se à mesma mesa e, mediante o diálogo construtivo facilitado por terceiro imparcial, possam chegar a um consenso racional, livre de qualquer coação ou coerção. Neste aspecto, a Teoria do Agir Comunicativo (2002), para a qual "os atos comunicativos - ações da fala ou externações não-verbais correspondentes - assumem a função de coordenar ações e contribuem para que se construam interações" (2002, p. 485) constitui, contemporaneamente, um dos fundamentos filosóficos destes métodos, oportunizando a solução construída e legitimada de modo autônomo, pelo consenso entre os conflitantes e não apenas aquela solução determinada por uma decisão judicial, heterônoma. As soluções criativas, oriundas dos próprios conflitantes, poderão ser objeto de diálogo, resultando do emprego de técnicas adequadas aplicadas pelo mediador ou conciliador, como a técnica das perguntas abertas, as quais nos remetem a fundamento mais remoto.

\section{A MEDIAÇÃO E A CONCILIAÇÃO NO DIREITO BRASILEIRO}

De acordo com Fiorelli J., Fiorelli M., e Malhadas Junior (2008), os métodos de gestão de conflitos são divididos em autocompositivos e heterocompositivos. Nos métodos autocompositivos, as partes almejam uma solução para o conflito sem a decisão de um terceiro, sendo exemplos, a mediação e a conciliação. Já nos métodos heterocompositivos, a solução do conflito é tarefa de um terceiro, ou seja, é de sua responsabilidade determinar o que as partes devem ou não fazer, sendo exemplos, o juiz Estatal (Poder Judiciário) e o árbitro (procedimento arbitral).

Segundo Sales (2004), vale salientar que a mediação se trata de um método de autocomposição assistida, em face de as próprias partes discutirem e comporem as controvérsias, no qual o mediador, considerado uma terceira pessoa imparcial, visa facilitar a comunicação entre elas através de técnicas próprias. 
Merece destacar que tal instituto encontra amparo legal na Lei Federal $n^{\circ} 13.140$, de 26 de junho de 2015, a qual "dispõe sobre a mediação como meio de solução de controvérsias entre particulares e sobre a autocomposição de conflitos no âmbito da Administração Pública". Tal legislação, não só regulamentou o instituto da mediação, como também previu a criação de câmaras de prevenção e resolução administrativa de conflitos, no âmbito da União, Estados, Distrito Federal e Municípios.

Fiorelli J., Fiorelli M., e Malhadas Junior (2008) definem a mediação como método mais recomendável no que diz respeito às situações consideradas crônicas, entendidas estas, como as que possuem elevado envolvimento emocional e necessidade de preservar os relacionamentos a partir de uma leitura dos acontecimentos, podendo ser aplicada na área ambiental, comunitária, vizinhança e cível, dentre outras.

De acordo com Sales (2010, p.3), são princípios da mediação: "liberdade das partes, não competitividade, poder de decisão das partes, participação de terceiro imparcial, competência do mediador, informalidade do processo e confidencialidade no processo". Assim sendo, pode-se afirmar, nesta ordem, que as partes não podem estar sofrendo qualquer tipo de ameaça ou coação, bem como não devem buscar uma competição, mas sim, o espírito de cooperação.

Como críticas à mediação, Spengler (2010) preceitua que se trata de um instrumento de resolução de conflitos relativamente novo, além do fato de que a verdade consensual se opõe à verdade processual, tendo em vista que a responsabilidade não recai em uma sanção, mas sim, na possibilidade de escolha das partes, na ausência da figura do juiz e na presença do mediador, considerado este, um guia para as partes no tratamento do conflito, porém, sem poder para impor uma decisão. Assim sendo, o princípio da autonomia não vem substituído pela autoridade de um terceiro, ou seja, a mediação é considerada um jogo sem árbitro, onde os próprios jogadores são os verdadeiros controladores da partida.

Sales (2010) afirma que a mediação possui vários objetivos, dentre os quais se destaca, a solução dos conflitos, a prevenção da má administração de conflitos, a inclusão social e a paz social. O primeiro dos objetivos anteriormente mencionado destaca que o diálogo é o melhor caminho para se atingir a solução do conflito e seu fundamento encontra respaldo na visão positiva do conflito, na cooperação entre as partes e na participação do mediador como facilitador dessa comunicação.

Vale ressaltar que é de extrema importância compreender a diferença entre conflito real e aparente, entendido este como conflito que não reflete o real problema, o que verdadeiramente está causando angústia, insatisfação, intranquilidade ou outro sentimento que 
provoque mal-estar. Diante disso, para melhor entender o conflito real, faz-se necessário buscar um aprofundamento da discussão, detectando no diálogo os interesses subjacentes e os valores dos conflitantes, para além do mero conflito de posições.

No que concerne ao segundo objetivo, conhecido por prevenção da má administração de conflitos, Sales (2010) preceitua que a mediação é considerada meio que tem o fito de facilitar o diálogo e trazer uma comunicação pacífica para as partes através do incentivo da conscientização de direito e deveres e da responsabilidade de cada indivíduo para a concretização dos mesmos. Já em relação à inclusão social, defende que a mediação é um meio de solução de conflitos que requer a participação efetiva das pessoas envolvidas no litígio com o intuito de solucionar problemas. Diante disso, tende a levá-las a dialogar e refletir sobre suas responsabilidades, direitos e obrigações.

Por fim, a paz social, conforme Sales (2010) é alcançada quando, na mediação, resolve-se e previne-se a má-administração dos conflitos, reforça a busca pelo diálogo quando se discute direitos, deveres e responsabilidade social, substituindo a competição pela cooperação. Portanto, a mediação tem a paz social como um de seus objetivos por ser vista como a forma pacífica de solução de conflitos, ou seja, para alcançá-la, devem estar presentes a figura da restauração, do diálogo pela comunicação não-violenta aliada à exigência e concretização de direitos.

Diante de tudo o que foi levantado anteriormente a respeito da mediação, pode-se afirmar que tal mecanismo de solução de conflitos não tem o intuito de substituir a função do Poder Judiciário, mas de auxiliá-lo. Logo, a relação é de colaboração por se tratar de um procedimento amigável baseado na política do ganha-ganha para ambas as partes. Prova disto é que o próprio Judiciário vem se valendo dele para tratar de modo mais adequado os conflitos judicializados.

Outro mecanismo de solução de conflitos similar à mediação é a conciliação. Ressalta Sales (2010) que a conciliação conta com o auxílio de um terceiro imparcial chamado conciliador, o qual tem a função de aproximar as partes, controlar as negociações, sugerir e formular propostas, bem como apontar vantagens e desvantagens com o fito de resolver o conflito por meio de um acordo. Uma das diferenças entre ambas é que na conciliação, o conciliador interfere na discussão entre as partes, sugerindo e propondo soluções para o conflito. Já na mediação, não há essa interferência, ou seja, enquanto que na mediação as partes conflitantes sugerem as soluções e o mediador facilita o diálogo e organiza as sugestões apresentadas, na conciliação, o conciliador adota uma postura mais ativa, sugerindo solução que as partes podem aceitar ou não. 
Além disso, é de fundamental importância, elencar algumas desvantagens em relação à conciliação conforme Fiorelli J., Fiorelli M., e Malhadas Junior (2008), as quais podem ser elencadas como sendo o poder elucidativo do processo que é considerado limitado. Ressalta-se ainda a questão da negociação tradicional, a qual visa ceder, transigir, trocar, permutar, barganhar, ou seja, cada uma das partes manifesta-se de uma forma, a qual pode não ser considerada a melhor para qualquer dos envolvidos.

Portanto, merece destacar que os tipos de conflitos mais adequados à solução pelo mecanismo da conciliação são aqueles nos quais as partes envolvidas não possuem vínculo afetivo, emocional anterior. Exemplo disso são os casos de colisão de veículos, de questões relacionadas a recálculo de dívidas etc.

No que tange à aplicação de tais mecanismos no Código de Processo Civil de 2015, merece destacar que o art. $3^{\circ}, \S 3^{\circ}$ do referido diploma, expressamente prevê tanto a mediação quanto a conciliação e outros métodos de solução consensual de conflitos, os quais devem ser estimulados sempre que possível por magistrados, advogados, defensores públicos, membros do Ministério Público. Assim sendo, percebe-se a importância que tais mecanismos têm adquirido no Direito Brasileiro com o fito de desafogar o Poder Judiciário e buscar uma maior celeridade e efetividade jurisdicional.

Para fazer cumprir esse ideal, os conciliadores e mediadores judiciais foram incluídos como auxiliares da Justiça, conforme preceituam os arts. 165 e 166, CPC/15 de maneira a regular a forma de atuação de ambos, atendendo aos princípios da independência, da imparcialidade, da autonomia da vontade, da confidencialidade, da oralidade, da informalidade e da decisão informada. Além disso, com fulcro nos arts. 167, §6 e 169, caput, CPC/15 ainda foi prevista remuneração para ambos, de acordo com tabela fixada pelo tribunal e parâmetros estabelecidos pelo Conselho Nacional de Justiça (CNJ), podendo ser criado quadro próprio de conciliadores e mediadores nos tribunais a ser preenchido por concurso público de provas e títulos. Vale ressaltar ainda, que se estabeleceu, aos tribunais, a criação de Centros Judiciários de Solução Consensual de Conflitos.

Sampaio Junior (2011) ressalta que é de fundamental importância a necessidade dos juízes passarem a se preocupar mais com a pacificação social em todas as suas decisões, na certeza de que não é com a sentença, no plano fático, que o conflito restará materialmente solucionado, tendo em vista que a ideia de que a decisão põe fim ao processo é apenas ilusória, pois, na maioria das vezes, não só deixa de resolver o problema específico do litígio (conflito real) como também cria outros conflitos, inviabilizando qualquer possibilidade de solução amigável por favorecer um ambiente de litigiosidade que dificilmente vai ser desconstruído. 
Segundo Kobayashi (2015), ainda se questiona se há estrutura para tais centros atualmente no Poder Judiciário, bem como se o suporte físico e financeiro dos Tribunais é suficiente para a implementação dos referidos espaços. Ressalta-se também que merece ponderação o que diz respeito à capacitação dos mediadores inscritos em tais centros, pelo fato de que a formação dos mesmos é regida pela Resolução ${ }^{\circ} 125 / 2010$, a qual exige o cumprimento de conteúdo programático mínimo, bem como reciclagem obrigatória de formação para aqueles que exercem tal função. Destarte, percebe-se que se exige um preparo devido e uma atenção especial nesses aspectos de forma a não contribuir no enfraquecimento de um instituto tão importante na resolução de conflitos trazido pelo CPC/15.

Assim sendo, como crítica levantada em relação aos Centros Judiciários, Franco (2015) aponta que o maior desafio do Poder Judiciário, bem como da União, dos Estados, do Distrito Federal e dos Municípios diz respeito à criação dos referidos Centros com pessoas capacitadas com o intuito de resolver conflitos nas várias áreas do Direito.

Ressalta-se ainda que o art. 319, VII, CPC/15 trouxe a opção do autor pela realização ou não de audiência de conciliação ou de mediação, a qual tem um procedimento descrito no art. 334, CPC/15, além de inovação trazida pela possibilidade de mediação nas ações que envolvem manutenção e reintegração de posse e nas ações de família, conforme arts. 565 e 694, CPC/15 respectivamente.

No que tange às audiências de conciliação ou de mediação, Pinto e Goulart (2015) ressaltam que o art. $334, \S 7^{\circ}, \mathrm{CPC} / 15$ prevê a possibilidade de sua realização por meio eletrônico, conforme previsão legal. No entanto, a crítica que se faz é que a videoconferência, além de encarecer e atrasar o processo, contradiz o que busca o próprio instituto da autocomposição que é a participação efetiva das pessoas envolvidas no litígio com o intuito de solucionar problemas, ou seja, a maior aproximação entre as partes.

Ribeiro (2011) critica que no CPC/15, a mediação e conciliação foram tratadas de forma similar, de modo que não foi dada a merecida distinção entre tais institutos. Percebe-se que ambos foram tratados como sendo uma atividade destinada à obtenção de um acordo. No entanto, diferentemente do conciliador, o mediador não propõe acordo, bem como não oferece solução para o conflito, mas sim, busca ajudar as partes como facilitador do diálogo entre elas. Logo, não seria razoável misturá-los na audiência initio litis. Diante disso, mediador e conciliador não merecem receber o mesmo tratamento no que tange ao registro, capacitação, certificação, dentre outros.

Por fim, Ribeiro (2011), manifesta seu pensamento crítico em relação à questão do momento para pagamento das custas e despesas judiciais ao afirmar que o CPC/15 deveria ter 
previsto que o adiantamento das custas iniciais seria feito após a retomada do curso do processo, caso não obtivesse êxito na realização de acordo. Todavia, se na audiência o acordo restasse frutífero, o pagamento deveria ser previsto de forma proporcional ou até mesmo ocorrer uma isenção, em face de se incentivar os mecanismos de tratamento adequado de conflitos.

Assim sendo, denota-se que apesar de existirem desvantagens, bem como críticas no Código de Processo Civil 2015 em relação aos meios de solução de conflitos, mais especificamente, no que diz respeito à mediação e à conciliação, estes são considerados instrumentos eficazes na atualidade, servindo de apoio, colaboração ao Poder Judiciário com o objetivo de desafogá-lo e acelerar a efetividade na prestação jurisdicional, embora estes não possam ser os seus fins precípuos, sob pena de inviabilização de tais métodos.

\section{APLICAÇÃO DA MEDIAÇÃO E DA CONCILIAÇÃ̃O NO PODER JUDICIÁRIO DO ESTADO DO CEARÁ: UM LONGO CAMINHO Ả SER SEGUIDO}

Diante do cenário vivido atualmente pelo Poder Judiciário, a busca por mecanismos alternativos de resolução de conflitos tem crescido cada vez mais. A mediação e a conciliação, em especial, encontraram ainda maior respaldo com o Código de Processo Civil de 2015. Assim, denota-se que tais mecanismos passaram a ser utilizados de forma a auxiliar a Justiça com o fito de desafogar e proporcionar maior celeridade jurisdicional.

Com isso, vale ressaltar como objeto de pesquisa na referida abordagem, os indicadores alcançados pela publicação Justiça em Números, do Conselho Nacional de Justiça do ano de 2016, tendo como base, o ano de 2015. Além disso, destaca-se ainda o trabalho desenvolvido pelo Núcleo Permanente de Métodos Consensuais de Solução de Conflitos (NUPEMEC) do Tribunal de Justiça do Estado do Ceará, bem como pelo Centro Judiciário de Solução de Conflitos (CEJUSC) do Fórum Clóvis Beviláqua.

\subsection{Nupemec do Tribunal de Justiça do Estado do Ceará}

Com base no portal eletrônico do Núcleo Permanente de Métodos Consensuais de Solução de Conflitos (NUPEMEC) do Tribunal de Justiça do Estado do Ceará (2016), é possível constatar que o Nupemec é composto por magistrados e servidores e tem o intuito de utilizar os meios alternativos de solução de conflitos, com ênfase na conciliação e mediação judiciais, com o fito de proporcionar um Judiciário mais célere e eficaz à sociedade. 
O referido Núcleo foi instituído mediante Provimento $n^{\circ}$ 03/2011 e Portaria $n^{\circ}$ 281/2011, em face da Resolução n ${ }^{\circ}$ 125/2010, do Conselho Nacional de Justiça, a qual dispõe sobre a política judiciária nacional de tratamento adequado dos conflitos de interesses no âmbito do Poder Judiciário.

Vale ressaltar, com base no Manual para Instalação do Centro Judiciário de Solução de Conflitos e Cidadania (2014), o Nupemec atua como órgão de inteligência, gestão e execução, cabendo-lhe cuidar da administração de toda prática que faz utilização dos métodos alternativos de resolução de conflitos, em especial, a mediação e a conciliação, tanto préprocessual quanto processual, no âmbito do Poder Judiciário cearense, coordenando os serviços desenvolvidos, bem como os recursos humanos através do acompanhamento do recrutamento e capacitação permanente dos conciliadores e mediadores.

De acordo com a publicação Justiça em Números, do Conselho Nacional de Justiça (2015, p.69), a Resolução n ${ }^{\circ}$ 125/2010 do CNJ instituiu os Núcleos Permanentes de Métodos Consensuais de Solução de Conflitos (NUPEMEC`s). No que tange à estrutura voltada para a conciliação, ao final do ano de 2014, a Justiça Estadual contava com 58 núcleos permanentes instalados, número este obtido porque cada tribunal da Justiça Estadual informou dispor de 1(um) núcleo, com exceção dos Tribunais de Justiça dos Estados de Pernambuco e do Acre que não possuem tal estrutura. Já o Tribunal de Justiça do Estado do Ceará e do Distrito Federal dispõem de 33 e de 2 núcleos nessa ordem. Conforme preceitua o art. $7^{\circ}$, da Resolução no 125 , de 29 de novembro de 2010 do Conselho Nacional de Justiça:

Os tribunais deverão criar, no prazo de 30 dias, Núcleos Permanentes de Métodos Consensuais de Solução de Conflitos (Nupemec), coordenados por magistrados e compostos por magistrados da ativa ou aposentados e servidores, preferencialmente atuantes na área.

Ainda prevê o art. $8^{\circ}$ da aludida Resolução:

Os tribunais deverão criar os Centros Judiciários de Solução de Conflitos e Cidadania (Centros ou Cejuscs), unidades do Poder Judiciário, preferencialmente, responsáveis pela realização ou gestão das sessões e audiências de conciliação e mediação que estejam a cargo de conciliadores e mediadores, bem como pelo atendimento e orientação ao cidadão.

Assim sendo, diante desta orientação, o Conselho Nacional de Justiça disciplina que os Tribunais criem NUPEMEC`S e CEJUSC`s, como determinam os arts. $7^{\circ}$ e $8^{\circ}$ da resolução já mencionada.

O Estado do Ceará tem apresentado bons índices a partir do trabalho desenvolvido pelo Nupemec, o qual tem utilizado mecanismos alternativos, em especial, a mediação e a conciliação, na solução de conflitos. Denota-se, com base no Quadro 1, a existência de vários 
litígios que deixaram de ser levados ao Poder Judiciário, tendo em vista o total de acordos exitosos realizados na esfera judicial somente na Semana da Conciliação no ano de 2015.

Quadro 1 - Semana da Conciliação 2015

\begin{tabular}{|l|c|}
\hline \multicolumn{1}{|c|}{ AUDIÊNCIAS } & ESTADO DO CEARÁ \\
\hline Total Geral de Audiências Agendadas & 21.735 \\
\hline Total Geral de Audiências Realizadas & 14.218 \\
\hline Total de Acordos & 5.817 \\
\hline Percentual de Acordos & $40,91 \%$ \\
\hline
\end{tabular}

Fonte: TJCE (2015)

Percebe-se no Quadro 1 que, somente na Semana da Conciliação, realizada no ano de 2015, foram realizadas 14.218 audiências, totalizando capital e interior do Ceará. Destas, 5.817 resultaram em acordos exitosos, representando um percentual de 40,91\% de efetividade.

Merece destacar que há uma tendência de aumento nos referidos percentuais, tendo em vista que o Código de Processo Civil de 2015 já entrou em vigor, prevendo a realização de audiência de conciliação e mediação como etapa obrigatória, anterior à formação da lide, como regra geral para todos os processos cíveis.

\subsection{Cejusc do Fórum Clóvis Beviláqua}

Com fulcro no Relatório de Gestão do Poder Judiciário do Estado do Ceará (2016, p. 1), “o Centro Judiciário de Solução de Conflitos e Cidadania (CEJUSC) do Fórum Clóvis Beviláqua em Fortaleza/Ceará foi criado em 2012, a partir da estrutura física da Central de Conciliação de $1^{\circ}$ Grau, em funcionamento desde 23 de março de 2007, por força da Resolução no 01/2007”.

Vale ressaltar que os maiores litígios que o CEJUSC recebe, são oriundos de processos das Varas Cíveis e de Família da Comarca de Fortaleza, sendo tal divisão necessária, em razão da competência, pois o que não é referente às Varas de Família, é atribuição legal das Varas Cíveis. Assim sendo, denota-se que as maiores demandas das Varas Cíveis se referem a revisionais de contratos bancários e questões imobiliárias e, em menor escala, a questões de vizinhança, reparações de danos, buscas e apreensões, enquanto que nas Varas de Família, os litígios se concentram em divórcio, pensão alimentícia, guarda e investigação de paternidade. Portanto, o CEJUSC atende demandas que envolvem direitos patrimoniais disponíveis e indisponíveis transacionáveis. 
O Relatório de Gestão do Poder Judiciário do Estado do Ceará (2016) ainda estabelece que em 2015, foram agendadas 1020 audiências, das quais, 477 foram realizadas e destas, 176 obtiveram êxito. Em relação ao ano de 2016, até o mês de setembro, foram agendadas 831 audiências, das quais, 465 foram realizadas e destas, 215 obtiveram êxito, conforme se observa no Gráfico 1:

\section{Gráfico 1 - Estatística Processual CEJUSC}

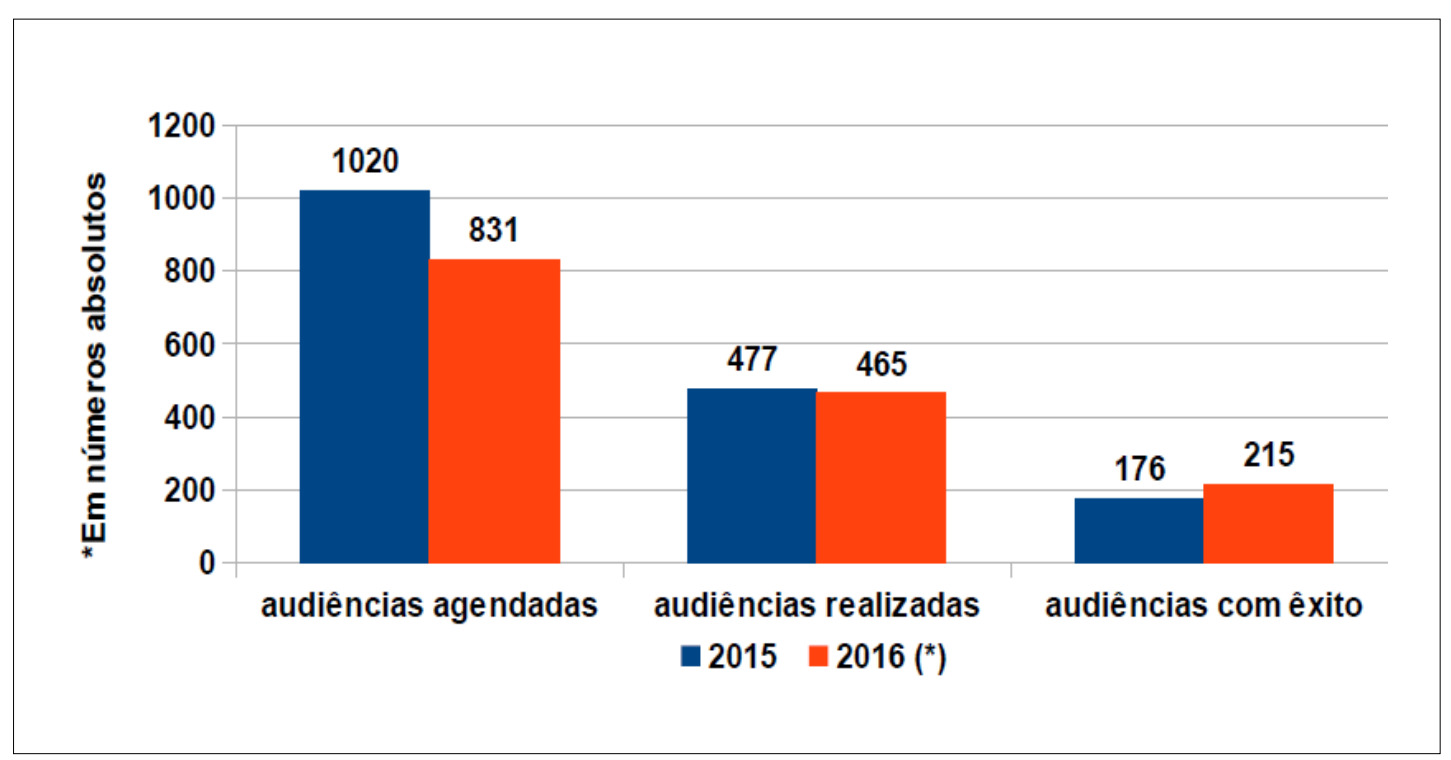

Fonte: CEJUSC (2016, p. 3)

A partir da análise do Gráfico 1, conclui-se que, mesmo traçando um paralelo entre todo o ano de 2015 e os 9 (nove) primeiros meses de 2016, ou seja, até o mês de setembro do referido ano, constata-se que houve aumento na taxa de efetividade das audiências realizadas, pois o número aumentou de 176 para 215 acordos com êxito. No entanto, vale inferir que ainda é considerado muito baixo o comparativo entre a efetividade nos acordos com o total de audiências realizadas e estas decrescem muito em face do total de audiências agendadas.

Gráfico 2 - Comparativo de êxito: Cível - Família

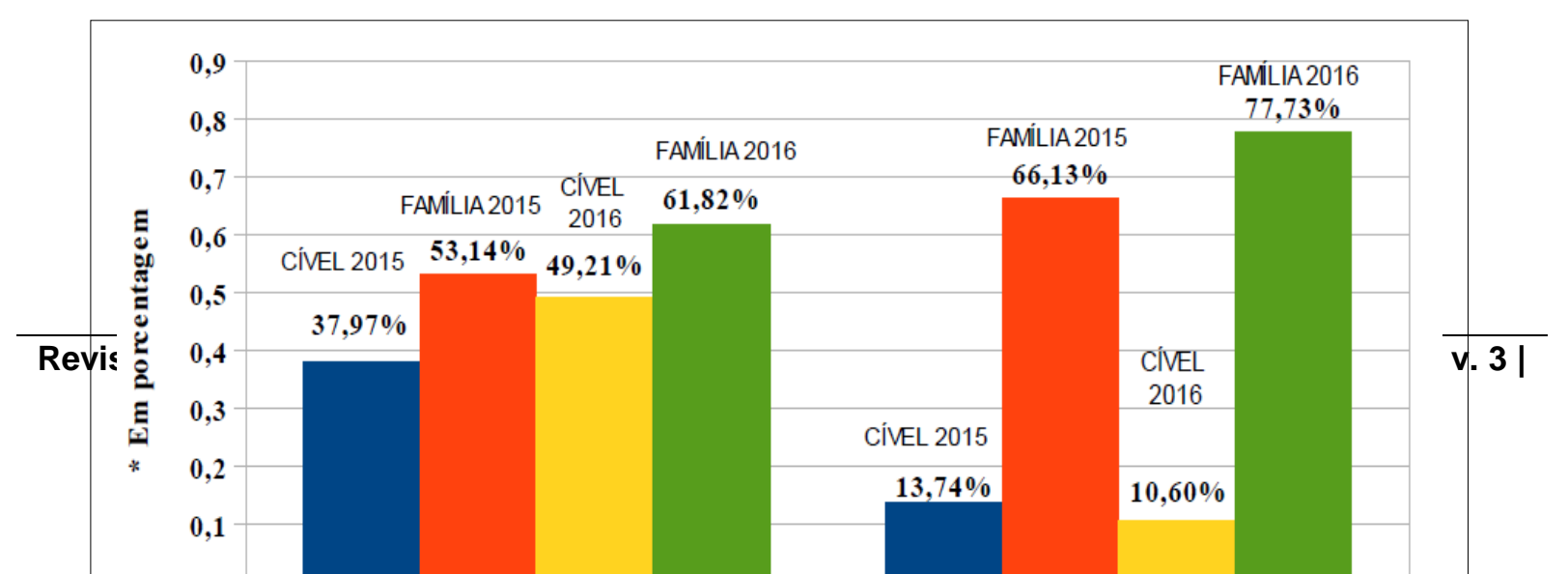


Fonte: CEJUSC (2016, p. 4)

Do Gráfico 2, infere-se que do total de audiências cíveis realizadas em 2015, foi obtido um percentual de $13,74 \%$ de êxito enquanto que nas audiências de família, esse percentual foi de 66,13\% de efetividade. Já até o mês de setembro de 2016, houve uma pequena queda no índice de êxito das audiências cíveis, já que seu percentual diminuiu para $10,60 \%$, porém, as audiências de família obtiveram um aumento, restando o percentual de $77,73 \%$ de desfechos satisfatórios. Merece destacar que o crescimento nos índices de audiências de família deve-se à própria natureza dos conflitos, os quais envolvem sentimentos, afetos, mostrando-se exitoso, portanto, o uso da mediação. Já no cível, o maior interesse é patrimonial, não sendo cabível a mediação, mas tão somente conciliação (método cujas técnicas estão focadas no acordo e não permitem aprofundar na causa dos conflitos).

Pode-se afirmar que o Estado do Ceará possuía apenas 4 CEJUSC`s instalados no ano de 2014, o que ainda era uma quantidade muito reduzida. A Resolução no 125/2010 do Conselho Nacional de Justiça veio contribuir com a instalação de CEJUSC's a nível nacional. Depois disso, só o Tribunal de Justiça do Estado do Ceará implantou 90 CEJUSC`s no ano de 2015 e, até o mês de novembro de 2016, foram implantados mais 35 outros Centros criados mediante Portaria, totalizando, portanto, 129 CEJUSC`s em todo o Estado. Merece destacar que é um grande avanço para o Ceará, tendo em vista que o Tribunal de Justiça do referido Estado é considerado de médio porte segundo os critérios do próprio CNJ. Porém, apresenta números de CEJUSC's criados que o aproximam de tribunais de grande porte, como o Tribunal de Justiça do Estado de São Paulo.

\subsection{Problemas ainda existentes}

Vale ainda ressaltar que os métodos de tratamento adequado de solução de conflitos têm crescido atualmente e auxiliado o Poder Judiciário no que tange à grande carga processual 
enfrentada, o que gera lentidão na prestação jurisdicional. Todavia, mesmo que os números desenvolvidos representem um grande passo, pode-se afirmar que o caminho é longo e precisa ser melhor construído de forma a utilizar a mediação e a conciliação como verdadeiros mecanismos que busquem a paz social, o espírito cooperativo no aprofundamento do conflito real, prezando pela qualidade na aplicação de suas técnicas.

A partir de uma análise dos números apresentados durante a Semana da Conciliação 2015, pode-se inferir por meio de uma leitura mais clara dos dados que o maior objetivo buscado tem sido a quantidade e não qualidade na realização das mediações ou conciliações, tendo em vista que o aspecto ainda merecedor de maior atenção é contabilizar para o Conselho Nacional de Justiça. Mesmo assim, observa-se que os números apresentados pelo Cejusc decrescem quando se leva em consideração a quantidade de sessões agendadas, realizadas e com êxito. Percebe-se que menos da metade das sessões realizadas obtiveram êxito, ou seja, resultaram em acordos efetivos, o que precisa ser melhor revisto e aprimorado.

Conforme Sampaio Junior (2011), para que os magistrados possam atuar de forma efetiva na mediação e na conciliação, devem ampliar seu conhecimento para além do Direito, buscando saberes de outras ciências através da interdisciplinaridade, a fim de melhor compreender as inquietudes e incoerências nas relações humanas.

Nessa mesma linha de raciocínio, Prado (2008) afirma que os concursos para seleção de juízes deveriam se preocupar mais com o ser humano interessado em ingressar na magistratura e menos com a possibilidade de decorar informações, dando início, assim, a verdadeira reforma do Judiciário, percebendo-se que para julgar um ser humano, o juiz precisa ser cada vez mais humano e, com isso, estaria mais aberto ao emprego das técnicas da mediação e da conciliação com o fito de se buscar a verdadeira paz social.

O mesmo vale também para a própria classe de advogados, pois ainda buscam o Judiciário como único canal para resolução do conflito, ou seja, têm ainda enraizada a cultura da litigiosidade e não da autocomposição para resolver a demanda do cliente.

Outro problema levantado é a questão de que, muitas vezes, a mediação é confundida com a conciliação e vice-versa. Vale ressaltar que, embora possuam natureza de autocomposição e visem diálogo entre os conflitantes para a possível costura do acordo, são considerados institutos diferentes, já que a mediação é mais utilizada, na prática, quando se identifica uma profundidade maior no litígio, enquanto que a conciliação é adotada quando a lide é mais superficial, genérica. Além disso, conciliador e mediador não deveriam receber o mesmo tratamento no que diz respeito ao registro, capacitação e certificação, devendo haver 
diferenciação e profissionalização destas atividades, bem como maior incentivo à permanente qualificação e atualização.

Ressalta-se ainda que no Ceará, nem todas as CEJUSC`s que foram criadas mediante portaria se encontram em pleno funcionamento, já que, muitas delas, ainda estão em fase de instalação, bem como não há ainda $100 \%$ de cobertura de tais Centros em todas as Comarcas do Estado do Ceará.

\section{CONSIDERAÇÕES FINAIS}

Como visto, em termos gerais, a crise vivida pelo Poder Judiciário brasileiro é decorrente de vários fatores, dentre os quais, pode-se enumerar: a má distribuição dos órgãos jurisdicionais, dos magistrados, defensores, promotores e servidores no território nacional, já que não se leva em conta as necessidades de cada região, bem como a falta de informatização em algumas localidades existentes do Poder Judiciário e o reduzido incentivo na criação de escolas e cursos de aperfeiçoamento, além do pouco estímulo aos mecanismos de tratamento adequado de conflitos, em especial, à mediação e à conciliação.

Confirmou-se, a partir de levantamentos realizados, que o Poder Judiciário apresenta o grande problema da morosidade, o qual se estende também na fase de execução dos processos e nos juizados especiais. Em regra, os últimos deveriam ser mais céleres em atendimento aos princípios da simplicidade, informalidade e economia processual, todavia, isto não ocorre na prática.

Diante de tal cenário, faz-se necessário uma maior busca, incentivo e aprimoramento na aplicação dos mecanismos alternativos à solução heterônoma, judicial, visto que é no $1^{\circ}$ grau de jurisdição que se concentra o maior número de processos. Todavia, a conciliação e a mediação ainda ocupam tímido papel como saída em busca da solução dos conflitos no âmbito da Justiça Estadual Cearense.

No que tange aos Centros Judiciários de Solução de Conflitos e Cidadania (CEJUSC`s), outro desafio para o Poder Judiciário, bem como para União, Estados, Distrito Federal e Municípios diz respeito à criação dos referidos Centros com pessoas capacitadas e estrutura adequada na intenção de resolver litígios nas diversas áreas da ciência jurídica, a fim de auxiliar o Poder Judiciário, sem a intenção de substituí-lo, procurando entendê-lo como um sistema multiportas, onde as partes podem ser trazidas para mais perto do Judiciário com o fito de resolver o real conflito e, assim, proporcionar maior efetividade e evitar o surgimento de 
novas demandas quando estas se mostrarem desnecessárias ante a possibilidade de autocomposição pré-processual.

Por fim, diante de todo o levantamento e estudo realizado, pode-se levar a pensar que os percentuais de efetividade no atendimento às demandas pelos mecanismos de tratamento adequado de conflitos no âmbito judicial foram considerados baixos em comparação a todo o universo de litígios existente, apesar do imenso investimento do Conselho Nacional de Justiça e dos Tribunais desde o ano de 2006 através de atos normativos, campanhas, sistemas e atividades de capacitação.

Apesar dos resultados ainda serem pouco expressivos, acredita-se que a difusão de tais métodos e a expansão dos CEJUSC's, com maior qualificação e profissionalização de mediadores e conciliadores são possíveis saídas para reduzir os problemas vivenciados pelo Poder Judiciário brasileiro no futuro próximo, em especial, no Estado do Ceará, ampliando as formas de acesso à justiça, inclusive de grupos vulneráveis e minorias. Por outro lado, o advento do Código Processual Civil de 2015 certamente incidirá positivamente neste índice, o qual só poderá ser melhor avaliado, nas próximas pesquisas realizadas e nos relatórios subsequentes do Conselho Nacional de Justiça.

\section{REFERÊNCIAS BIBLIOGRÁFICAS}

BRASIL. Constituição (1988). Constituição da República Federativa do Brasil. Brasília, DF: Senado, 1988.

. Lei ${ }^{\circ} 13.105$, de 16 de março de 2015. Código de Processo Civil. Diário Oficial da União, Brasília, DF, de 17 de março de 2015.

Lei n ${ }^{\circ} 13.140$, de 26 de junho de 2015. Dispõe sobre a mediação entre particulares como meio de solução de controvérsias e sobre a autocomposição de conflitos no âmbito da administração pública; altera a Lei no 9.469, de 10 de julho de 1997, e o Decreto no 70.235, de 6 de março de 1972; e revoga o § 2o do art. 6o da Lei no 9.469, de 10 de julho de 1997.

Diário Oficial da União, Brasília, DF, de 29 de junho de 2015.

Emenda Constitucional $n^{\circ} 45$, de 30 de dezembro de 2004. Altera dispositivos dos arts. $5^{\circ}, 36,52,92,93,95,98,99,102,103,104,105,107,109,111,112,114,115,125$, 126, 127, 128, 129, 134 e 168 da Constituição Federal, e acrescenta os arts. 103-A, 103B, 111-A e 130-A, e dá outras providências. Diário Oficial da União, Brasília, DF, de 31 de dezembro de 2004.

CAPPELlETTI, Mauro; GARTH, Bryant. Acesso à justiça. Tradução de Ellen Gracie Northfleet. Porto Alegre: Fabris, 1988. 
CARVALHO, José Murilo de. Cidadania no Brasil: o longo caminho. 10. ed. Rio de Janeiro: Civilização Brasileira, 2008.

CEARÁ. Tribunal de Justiça do Estado do Ceará (TJCE). Manual para Instalação do Centro Judiciário de Solução de Conflitos e Cidadania. Fortaleza, 2014. Disponível em: <http://www.tjce.jus.br/wp-content/uploads/2016/06/ManualparaCejusc colorido.pdf.pdf>. Acesso em: 05 mar. 2017.

Tribunal de Justiça do Estado do Ceará (TJCE). Núcleo Permanente de Métodos Consensuais de Solução de Conflitos do Poder Judiciário do Estado do Ceará. Disponível em: < http://www.tjce.jus.br/nupemec/>. Acesso em: 04 fev. 2017.

Tribunal de Justiça do Estado do Ceará (TJCE). Relatório Global Totalização. Semana da Conciliação 2015. Disponível em: <http://10.1.1.143/conciliacao/ paginas/RelatorioConciliacao3.asp>. Acesso em: 01 mar. 2017.

CENTRO JUDICIÁRIO DE SOLUÇÃO DE CONFLITOS E CIDADANIA (CEJUSC). Relatório de Gestão do Poder Judiciário do Estado do Ceará. Fórum Clóvis Beviláqua, 2016.

CONSELHO NACIONAL DE JUSTIÇA (CNJ). Justiça em Números 2015: ano-base 2014. Brasília, 2015. Disponível em: <http://www. cnj.jus.br/programas-e-acoes/pj-justica-emnumeros >. Acesso em: 22 fev. 2017.

Resolução no 125 de 29/11/2010. Dispõe sobre a Política Judiciária Nacional de tratamento adequado dos conflitos de interesses no âmbito do Poder Judiciário e dá outras providências. Disponível em: 〈http://www.cnj.jus.br/busca-atos-adm?documento=2579>. Acesso em: 07 abr. 2017.

FIORELLI, José Osmir; FIORELLI, Maria Rosa; MALHADAS JUNIOR, Marcos Julio Olivé. Mediação e solução de conflitos: teoria e prática. São Paulo: Atlas, 2008.

FRANCO, Cintia. A solução consensual de conflitos no novo Código de Processo Civil. DireitoNet. 22 mar. 2015. Disponível em: <http://www.direitonet.com.br/artigos/exibir/ 9012/A-solucao-consensual-de-conflitos-no-novo-Codigo-de-Processo-Civil>. Acesso em: 07 fev. 2017.

HABERMAS, Jürgen. Teoria do agir comunicativo. Trad. Flávio Beno Siebeneichler. São Paulo: WMP Martins Fontes, 2002.

JORGE NETO, Nagibe de Melo. Abrindo a Caixa Preta: Por que a Justiça não funciona no Brasil?. Salvador: Juspodivm, 2016.

KOBAYASHI, Fernanda Mayumi. A mediação no novo CPC: estão todospreparados. Justificando. 25 maio. 2015. Disponível em: $<$ http://justificando.com/2015/05/25/a-mediacaono-novo-cpc-estao-todos-preparados/>. Acesso em: 09 abr. 2017. 
MAIA FILHO, Napoleão Nunes. Direito à Justiça: normose processual ou falência do formalismo na promoção da eficácia dos direitos. Fortaleza: Imprece, 2015.

OLIVEIRA NETO, Emetério Silva de. Fundamentos do Acesso à Justiça: conteúdo e alcance da garantia fundamental. Rio de Janeiro: Lumen Juris, 2016.

PINTO, Bernardo Serra Moura; GOULART, Leandro Henrique Simões. A autocomposição sob a ótica do Novo Código de Processo Civil: o encaixe da mediação e da conciliação na nova sistemática processual. Newton- Pós em Revista. 25 maio. 2015. Disponível em: $<$ http://blog.newtonpaiva.br/pos/e10-dir02-a-autocomposicao-sob-a-optica-do-novo-codigode-processo-civil-o-encaixe-da-mediacao-e-da-conciliacao-na-nova-sistematica-processual/> . Acesso em: 09 mar. 2017.

PRADO, Lídia Reis de Almeida. O juiz e a emoção: aspectos da lógica da decisão judicial. 4. ed. Campinas: Millennium Editora, 2008.

RAWLS, John. Uma teoria da justiça. Tradução de Vamireh Chacon. Brasília: Universidade de Brasília, 1981.

RIBEIRO, Flávia Pereira. A introdução da audiência initio litis - de conciliação ou mediação no Código de Processo Civil. Revista de Informação Legislativa, Brasília, n.190, Ano 48, p.179-187, abr./jun. 2011.

SALES, Lilia Maia de Morais. Justiça e Mediação de Conflitos. Belo Horizonte: Del Rey, 2004.

Mediare: um guia prático para mediadores. 3. ed. Rio de Janeiro: GZ, 2010.

SAMPAIO JUNIOR, José Herval. O papel do juiz na tentativa de pacificação social: a importância das técnicas de conciliação e mediação. Revista Opinião Jurídica, Fortaleza, n. 13, ano IX, p. 153-181, jan./dez.2011.

SAUERBRONN, Fernanda Filgueiras; SAUERBRONN, João Felipe Rammelt.

Representações sociais da reforma do Judiciário - um estudo baseado nas perspectivas dos servidores do Tribunal de Justiça do Estado da Bahia. Revista de Administração

Pública, [s.l.], v. 49, n. 3, p.719-737, jun. 2015. Disponível em: <http://dx.doi.org/ 10.1590/0034-7612130108> Acesso em: 19 mar. 2017.

SCHNITMAN, Dora Fried. Novos paradigmas em mediação. Trad. Marcos A. G. Domingues e Jussara Haubert Rodrigues. Porto Alegre: Artes Médicas Sul, 1999.

SCHUARTZ, Stuart. Burocracia e sociedade no Brasil colonial: o Tribunal da Relação da Bahia e seus desembargadores, 1609-1751. Trad. Berilo Vargas. São Paulo, Companhia das Letras, 2011.

SPENGLER, Fabiana Marion. Mediação: um retrospecto histórico, conceitual e teórico. In: Mediação enquanto política pública: a teoria, a prática e o projeto de lei. (Org.). Spengler, Fabiana Marion; Spengler Neto, Theobaldo. Santa Cruz do Sul: Edunisc, 2010. Disponível em: 
<http://ead.tjrs.jus.br/navi_tjrs/agenda/pdf.php? COD_ARQUIVO=4309>. Acesso em: 19 abr. 2017. 